\title{
OBSERVATÓRIO DA TRANSFORMAÇÃO URBANA DO SOM: A CIDADE ENQUANTO TEXTOS, DERIVAS, MAPAS E CARTOGRAFIA SONORA
}

\author{
Josep Cerdà ${ }^{1}$ \\ Tradução e revisão ${ }^{2}$ : \\ Fidel Cañas ${ }^{3}$; Maurício Panella ${ }^{4}$; \\ Miguel Gally ${ }^{5}$; Tiago Mendes ${ }^{6}$.
}

\begin{abstract}
Resumo
O projeto cartografia sonora: observatório de transformação urbana do som está centrado na análise do ambiente sonoro em zonas de tensão e conflito, onde foram produzidas mudanças bruscas de transformação urbana, movimentos migratórios, zonas de fricção ou articulação entre o urbano e a natureza. $\mathrm{O}$ ambiente sonoro dos espaços urbanos está definido por marcas sonoras e os traços acústicos da mobilidade que se misturam no espaço auditivo. O espaço público é uma composição sonora em transformação e é também um reflexo das mudanças estruturais da sociedade. A cartografia artística representa fluxos visíveis e invisíveis que unem a experimentação e a interpretação da realidade cotidiana, que operam simultaneamente em uma esfera global e local. A informação coletada apresenta-se em múltiplas camadas e marca uma trama de relações que configuram um mapa sonoro. A finalidade é decodificar a informação sonora da cidade como um elemento que se manifesta com camadas sobrepostas e em constante transformação. Aplica-se uma capacidade organizacional da arte mediante estratégias de observação de uma realidade flutuante e difusa.
\end{abstract}

Palavras chave: Arte sonora, cartografia sonora, paisagem sonora.

\footnotetext{
1 Escultor, artista multimidia e professor do Departamento de Escultura da Faculdade de Belas Artes da Universidade de Barcelona (UB), Diretor e Coordenador do grupo de pesquisa MESCA (Mestiçagem Cultural e Artística), da Divisão de Ciências Humanas e Sociais da UB. Email: cerda@ub.edu.

${ }^{2}$ Colaboraram com a tradução e revisão: Danilo Fleury (UnB/NEHS) e Rodrigo Faria (FAU/Unb). As citações feitas pelo autor em francês no artigo também foram traduzidas para o português e indicadas pelos tradutores; as citações, cujos textos originais eram em língua alemã, receberam uma tradução direta (sendo as edições usadas incluídas nas referências). Demais citações respeitaram o formato original do artigo: CERDA, Josep. "Observatorio de la transformación urbana del sonido: La ciudad como texto, derivas, mapas y cartografía sonora". Arte y Politicas de Identidad(Murcia), Vol 7(2012), pp. 143-161.

${ }^{3}$ Mestrando pelo Programa de Pesquisa e Pós-graduação em Linguística Aplicada da Universidade de Brasília.

${ }^{4}$ Antropólogo, sociólogo e artista multimídia. Doutorando pela Facultad de Bellas Artes de Granada- Espanha. Pesquisador NEHS/Unb.

${ }^{5}$ Professor de Estética da Faculdade de Arquitetura e Urbanismo da Universidade de Brasília.

${ }^{6}$ Arquiteto e Urbanista pela Faculdade de Arquitetura e Urbanismo da PUC/GO. Mestrando pela PPG-FAUUnB. Membro do Núcleo de Estética, Hermenêutica e Semiótica - NEHS. Este trabalho contou com a colaboração da Coordenação de Aperfeiçoamento de Pessoal de Nível Superior - CAPES.
} 


\section{INTRODUÇÃO}

"No leaft doth tremble, no ripple is there" (keats, 2010, p.132)

Este artigo trata de contribuir com uma visão do espaço urbano mediante conceitos de mapeamento e cartografia artística que fazem referência à representação de processos dinâmicos do território mediante informações em múltiplas camadas destinadas a ordenar, transmitir e processar informação. O projeto "Cartografia Sonora: Observatório de Transformação Urbana do Som" está centrado na análise do ambiente sonoro em zonas de tensão e conflito, onde se produziam mudanças bruscas de transformação urbana, movimentos migratórios, zonas de fricção ou articulação entre o urbano e a natureza. Cada cidade, bairro ou rua têm um ambiente sonoro particular que vai se transformando e adaptando no tempo. Toda mudança em um meio ambiente, natural ou cultural, implica em uma mudança sonora. Um dos elementos básicos no qual se pode detectar as transformações em um entorno urbano é no som: as migrações e as mudanças sociais comportam novos sons que se detectam nos edifícios e nas ruas.

O estudo das transformações urbanas por meio do som mediante sistemas de cartografia artística é realizado pelo grupo de pesquisa BR::AC - Barcelona, Recerca, Art $i$ Creació - da Universidade de Barcelona juntamente com o GIIP - Grupo Internacional e Interinstitucional de Pesquisa em Convergência entre Arte, Ciências e Tecnologia - do Instituto de Artes da Universidade Nacional do Estado Paulista, UNESP de São Paulo, Brasil. O projeto está centrado na análise do ambiente sonoro do bairro Raval de Barcelona a partir das transformações urbanísticas e repercussão social que se desenvolve por meio das novas migrações dos últimos dez anos. A área de estudo se concentra no entorno da Praça Salvador Seguí de Raval de Barcelona, onde está situada a nova Filmoteca da Catalunya.

A proposta é apoiada pelos trabalhos que realizamos na disciplina "Laboratori Del Caos" ministrada na Licenciatura de Bellas Artes da Universidade de Bracelona, e também por meio da disciplina "Paisatge Sonor i Espais de Ressonáncia" do Máster Oficial de Creación Artística, assim como também pelas experiências levadas a cabo na disciplina "Instalación Sonora" do Máster em Arte Sonoro da Universidade de Barcelona. A partir desta experiência, juntamente com Rosangella Leote e Lilian Amaral, artistas e docentes da Universidade Nacional do Estado Paulista de São Paulo, Brasil, organizamos o Workshop 
Internacional "Zonas de Compensação, R.U.A. Realidade Urbana Aumentada" que se realizou em São Paulo (maio, 2012) e em Barcelona (outubro, 2012).

O ambiente sonoro dos espaços urbanos está definido pelas marcas sonoras e traços da mobilidade que se misturam no espaço auditivo. O espaço público é uma composição sonora em transformação e também um reflexo das mudanças estruturais da sociedade. Existe uma identidade sonora em cada lugar, que configura a memória sonora e o subconsciente coletivo de seus habitantes. Cada cidade, bairro ou rua têm um ambiente sonoro particular que vai se transformando e adaptando no tempo. Os limites das mudanças e transformações dos sons são imprecisos já que são um reflexo direto de uma grande complexidade. Trabalhamos estes sons como material artístico, tal como indica Martin Seel em Estética Del Aparecer:

\begin{abstract}
A maioria dos objetos da arte consistem num emprego [Verwendung] específico de um material sensível (...) O material constitutivo de um tipo de arte é uma condição sem a qual nenhuma obra dessa arte pode ser dada (...) 'Material'[Material] não quer dizer 'matéria' [Materie], mas sim isso que é processado ou com o que se tem de trabalhar, e a partir do que se pode dizer ser a arte de um gênero determinado (...) Enquanto material da música seriam ruídos e sons. (SEEL, 2003, p.17377).
\end{abstract}

Esse estudo pretende decodificar uma informação sonora da cidade como um ente mutável, sobreposto e difuso. Os novos usos do espaço urbano e a diversidade de seus habitantes comportam novos sons que se detectam imediatamente nos edifício e nas ruas. As fronteiras, os níveis e as camadas de som são os eixos estruturais deste projeto artístico.

A cartografia artística é uma representação da realidade relacionada com o movimento e a mudança. A informação refletida se apresenta em múltiplas camadas e marca uma trama de múltiplas relações ocultas que configuram a realidade social. Um mapa sonoro é a intepretação gerada pela interação de várias camadas que se manifestam simultaneamente, contudo, não estão necessariamente conectadas ou formam uma unidade.

\title{
2. A CIDADE COMO TEXTO
}

A cidade é uma construção móvel, um cenário onde se desenvolvem nossas vivências. A cidade pode ser lida como um texto, esta formulação tem sido desenvolvida em produções literárias e nos trabalhos de artistas atuais que, como flaneurs ou exploradores

\footnotetext{
${ }^{7}$ Tradução direta do alemão por M.Gally.
} 
contemporâneos, navegam dentro desse espaço multidimensional onde transcorrem diversas realidades sobrepostas.

Nossa concepção do espaço contemporâneo não é um lugar homogêneo ou contínuo, não tem limites definidos, e está composto por pedaços ou fragmentos e a continuidade é estabelecida por nosso cérebro mediante relações. Os lugares são, por consequência, uma relação sonora, textual, sentimental. Ler esta realidade é colocar em contato aspectos imprevistos, mais próximos do imaterial do que do físico.

A cidade é um texto com infinitas possibilidades de leitura, e necessita-se de um mapa que seja uma representação da realidade. Esta representação do indefinível é uma necessidade de capturar nosso olhar pessoal e fixar os diversos percursos realizados na cidade dentro da cidade.

Percorrer o mapa, prática habitual das ações artísticas no território, tem a finalidade de relacionar conhecimento com experiência. A informação do percurso ou da deriva proporciona uma experimentação direta no espaço que nos faz ver que a cidade é multidimensional, com relações complexas não evidentes em outras partes.

Cada lugar tem memória. Os lugares são seus sons, seus cheiros ou imagens que passam pela peneira de nossa memória, quer dizer, têm uma dimensão além da física. A cidade é um espaço nem sempre delimitado. Essa experiência não pode ser representada mediante a perspectiva clássica do mapa, uma das funções do artista é mostrar essa diferente visão da realidade. Aqui, a palavra "desvelar" adquire um novo significado: a cidade se configura pela somatória de lugares para a interpretação e, muitas vezes, na arte contemporânea das últimas décadas, o artista tem sido um construtor de lugares.

O mestre indubitável e inevitável da leitura da cidade é Georges Perec, pesquisador infatigável do infraordinário, do trivial, do cotidiano, do comum, do evidente. Seu método: questionar o habitual, aquela parcela de realidade marcada pelo cotidiano e, precisamente, por essa imersão no cotidiano, permanece invisível a nossos olhos e ouvidos. Perec questiona o mais banal e comum para recuperar o assombro que não está nos grandes acontecimentos e notícias, e sim no essencial, o que realmente ocorre, o que vivemos é o significativo. Faz-nos perguntas simples e efetivas: façam um inventário de seus bolsos, de suas bolsas, interrogue sua procedência, o uso, o devenir de cada objeto. $O$ importante são as perguntas fragmentárias, triviais e vagas que são as que nos dão respostas essenciais para captar nossa realidade. 
Desde quinta-feira, 27 de fevereiro de 1968 até 27 de setembro de 1975, George Perec passeia pela Rue Vilin de Paris e faz uma descrição do que percebe. Essas descrições sequenciais nos mostram as mudanças ocorridas neste lugar durante esses sete anos. A descrição minuciosa dos detalhes mais ínfimos contrói um quebra-cabeça da vida deste lugar em transformação constante. Em "Espécies e Espaços" faz uma dissecação do que nos rodeia: a cama, a casa, o apartamento, o imóvel, a rua, o bairro, a cidade, o campo, o país, Europa, o mundo, o espaço. O capítulo do imóvel se desenvolverá em seu romance favorito: "La vida instrucciones de uso", uma descrição dos detalhes íntimos de cada habitação, de cada apartamento de um imóvel parisiense relatando a procedência e o movimento de cada objeto no tempo.

\section{TRAJETÓRIAS}

Os primeiros artistas que experimentaram o mapa com seus corpos foram os que desenvolveram a ideia da Deriva enquanto ato artístico e transgressor com a finalidade de compreender o território mediante o movimento. Esses artistas foram os primeiros que necessitaram capturar suas deambulações em diagramas, esquemas ou mapas. É nessa necessidade de fixar um movimento e uma trajetória como experiência corporal no espaço que aparecem os primeiros mapas psicogeográficos.

As excursões dos Dadaístas (1921) se estabeleciam como um movimento ao acaso destinado a buscar uma percepção diferente da cidade. Foram os precursores da exploração enquanto leitura dos espaços urbanos e precedentes de muitas das ações artísticas que tinham a cidade enquanto lugar de experimentação. Os Dadaístas, com Tristán Tzara em seu comando, foram o que ultrapassaram os limites da cidade para descobrir os espaços vizinhos: La Banlieue, onde começa outra realidade, o campo, a natureza ou simplesmente os Terrain Vagues, a terra de ninguém onde se situarão as ações conclusivas de seus passeios artísticos.

Nessa busca de uma nova percepção da cidade, Tristán Tzara costumava concluir com um simples ato de ler uma página do dicionário Larousse escolhida ao acaso. Marcel Duchamp, anos mais tarde, define exatamente o que esses artistas estavam fazendo: tomar consciência do que estão fazendo, Nada.

Os mapas psicogeográficos enquanto obra artística foram uma criação surrealista (1924) e partem da necessidade de configurar os passeios e trajetórias, de refletir as ações e 
sensações sobre um suporte legítimo. Ainda que os primeiros mapas fossem para se perder na cidade de Paris, a finalidade era o descobrimento de uma nova realidade marcada pelo automatismo e pela leitura de cidade inconsciente, o que é o mesmo que nossa percepção onírica da cidade.

A finalidade do surrealismo é se questionar em relação a realidade cotidiana e a arte é o instrumento dessa busca. O surrealismo vai de encontro com o conservadorismo social e, sobretudo, vai de encontro com o cotidiano, ou seja, esse conjunto de ações repetidas até a saciedade ou ações sem sentido. Pôr em questão nossa vida cotidiana leva esse coletivo de artistas a inventarem o automatismo para fazer aflorar o oculto, o invisível. É por isso que esse surrealismo primogênito atua à margem de qualquer censura e fora do sistema oficial de valores sociais. Essa corrente transgressora tem seus pontos de partida e relações nos sonhos, na loucura, na imaginação, nos estados alterados de consciência, na alucinação, na fantasia, como ato transgressor.

Enfim, a criação artística, na sua véspera, por meio das relações estreitas que ela mantém com a criação subconsciente do sono e do sonho, não é, e é preciso enfatizar, não permitirá nunca estar nessas duas soluções, a solução do real e a solução imaginária, uma total discriminação. (Breton, 1993, p.127)

No entanto, a ideia da psicogeografia e mapeamento artístico, tal como a entendemos atualmente, vem de uma corrente liderada por Guy Debord, a Internacional Situacionista (1958), que busca uma sequencia narrativa na leitura da cidade como texto. Ainda que este projeto artístico renegue seus antecessores a aposte por uma arte mais politizada, é certo que, visto sobre a perspectiva da perspectiva histórica a estrutura pela qual se sustenta os Situacionistas são uma evolução natural de seus antecessores Dadaístas e Surrealistas, que estabelecem a realidade cotidiana como material de suas ações artísticas.

O situacionismo é um método de construção de situações, tal como expressam em 1961: “Construcción de Situaciones Es la Liberación de las Energías Inagotables Contenidas en la Vida Cotidiana Petrificada" ( $\mathrm{n}^{\circ} 6$ de Internationale Situationiste). Essa experiência artística anárquica, em que a poesia é o expoente máximo, define-se desde o princípio com o fim de construir deliberadamente uma organização coletiva de um ambiente e um jogo de

\footnotetext{
${ }^{8}$ Tradução do francês, M.Gally.
} 
acontecimentos (Definiciones $n^{o} 1$ de Internationale Situationiste, de 1958). Neste mesmo número da Internacionale Situacioniste se define claramente o que é a psicogeografia para eles: o estudo dos efeitos precisos do meio geográfico (consciente ou não) que atua diretamente sobre o comportamento afetivo dos indivíduos.

A psicogeografia é, portanto, a influência da geografia sobre o comportamento afetivo das pessoas, e Guy Debord propõe um estudo das leis e dos efeitos do meio geográfico ( ${ }^{\circ} 6$ de Internationale Situationiste, 1955). Os situacionistas, que não se reconhecem como artistas, e sim experimentadores, criam uma ação artística que tem tido grande repercussão: a dérive, comumente conhecida como deriva.

A deriva é um passeio sem propósito guiado pelo acaso, é o comportamento experimental da ação de traspassar a rede urbana com nosso corpo, uma ação direta sem traduções nem representações da realidade. Para os situacionistas, a deriva também é a medida temporal dessa experiência.

\footnotetext{
Como dizia Perejaume [...] conforme passam os anos, os seres humanos temos sido aperfeiçoados como sujeitos e instrumentos de caminho, definitivamente como passeadores. Quiçá seja verdade, então, que é no caminho e atuando como passeadores onde melhor podemos reconhecer aquilo que nos faz humanos. (Nogué, 2009, p. 41)
}

Se o mapa é uma representação da realidade, a deriva é sua experimentação direta e pessoal desta realidade: andamos o mapa, experimentamos as mudanças de uma rua, as diversas atmosferas psíquicas, e estabelecemos diferentes níveis de atração ou repulsão pelos espaços, quer dizer, damos um componente afetivo aos espaços.

A história da dérive e a ideia de andar o mapa enquanto experiência artística teve um acompanhamento e evolução por todo o século XX. Nos anos 90 surge o grupo Stalker, criado por Francesco Carreri e sua característica peculiar é que seu local de experimentação se desloca dos limites administrativos das cidades aos lugares marginais, às periferias esquecidas pelas administrações, às terras de ninguém.

É nessa fronteira onde a periferia se converte em não-cidade, é nesse arquipélago fractal onde aparecem as hortas ilegais, onde saem para passear com os cachorros, ou que se enchem de pessoas fazendo piquenique nos fins de semana, onde os integrantes do grupo Stalker estabelece seu lugar de ação e experimentação artística. 
O grupo Stalker tem ramificações em todas as partes do mundo, em Barcelona é o Observatorio ON (Observatori Nomade) que recupera a viagem como descobrimento e o olhar do explorador e viajante genuíno cheio de surpresa. A finalidade é caminhar ou percorrer o mapa como experiência artística. $\mathrm{O}$ resultado será a experiência direta e física, assim como a amostragem de tal movimento: imagens fotográficas, escritos e gravações de sons.

A ordenação dessa documentação é uma cartografia do deslocamento do grupo de artistas nas fronteiras difusas do território. A paisagem é a possibilidade de milhares de possibilidades de coleta, a ação pessoal de escolher uma ou outra opção resultará em uma percepção diferente deste lugar. A ação de atravessar o espaço é uma ação artística onde a percepção sensorial entra em jogo.

As ações do grupo Stalker acontecem em territórios inexplorados ou mutantes, em espaços esquecidos das cidades, zonas abandonadas ou em processo de transformação que representam lugares ocultos, que subtraem a memória coletiva e que contém a memória reprimida do inconsciente.

Como proposto por Merleau Ponty, atualmente não se trata de proporcionar mais informação, o que de fato é necessário e dar testemunho. Estabelecer esse testemunho é o que pretendem as ações artísticas no território.

Nas conversas do cientista Enric Canadell e o artista plástico Àlex Nogué, sai o tema da necessidade de estabelecer um testemunho no ato artístico:

EC - E porque os dados cartográficos?

AN - A informação no texto abaixo indica a localização exata, coordenadas, em que o desenho é feito, a altura do nível do mar, bem como a data e hora. É uma maneira de dar fé de que o que você viu lá nesse momento. A confirmação da sua veracidade. (Nogué/ Canadell, 2010, p. 58)

Em um mundo com excesso de informação não direcionada, o mundo da arte estabelece critérios e leituras do que nos circunda, que são tão necessários como as explicações e conceitos que a ciência nos fornece.

A não-cidade é - para fins de uma ilustração - o que consegue fotografar Harvey Keitel em "Smoke", segundo um roteiro de Paul Auster, a cada manhã, as oito em ponto, o vendedor de tabaco dispara sua câmera sobre o que acontece naquele instante em frente à esquina em que se encontra sua loja. (Delgado, 2007, p. 73) 
É nessa fronteira entre arte e ciência que se desenvolvem muitas das pesquisas e experiências em ecologia acústica e arquitetura sonora.

Le Cresson é um centro de pesquisa sobre o espaço sonoro e o entorno urbano da Escola Nacional Superior de Arquitetura de Grenoble. É um dos centros internacionais com mais prestígio e que desde os anos 90 vem gerando estudos de campo quase exclusivamente centrados nos ambientes sonoros. Dentro dessa especialidade é interessante comprovar que a maioria de seus estudos se concentra no tema dos trajetos, dos deslocamentos, das composições sonoras dos percursos feitos a pé, dos transportes urbanos, das cartografias sensíveis das novas urbanizações, da experiência sonora das viagens nas rodovias, dos sons dos espaços públicos ao longo das linhas de bondes, que transformam os sons das obras e músicas urbanas em elementos de vículo.

Le Cresson dá uma extrema importância à percepção ocorrida in situ, uma característica primordial desse centro é que os pesquisadores, experimentando o lugar com seu próprio corpo, reforçam essa percepção subjetiva com métodos pluridisciplinares, onde se juntam elementos das áreas de conhecimento de arquitetura, arte, e as ciências sociais, assim como os ramos mais científicos da engenharia, física e ecologia.

\section{MAPAS}

Cada sistema de representação, segundo Deleuze, é uma possibilidade ou capacidade de organização do mundo, e com esta organização também estamos estabelecendo uma hierarquia no que nos rodeia. Um mapa ordena, processa e transmite informação, mas a tipologia da informação que queremos fixar está associada a nossa capacidade de formar ou deformar a realidade, que, definitivamente, é um reflexo da nossa visão de mundo. Isto é demonstrável por si mesmo com uma revisão histórica da cartografia mostrando que, em cada época histórica, os mapas foram um reflexo e uma projeção dos desejos e dos medos das sociedades humanas e das civilizações.

Uma cartografia é uma maneira de apropriação de um território, e esta apropriação pode ser física, mental ou sensorial. É este o sentido que lhe damos neste artigo, quando falamos de cartografia; não o fazemos sob a epígrafe de uma cartografia científica, exata e unívoca, mas sim com uma definição de cartografia aberta, versátil e abstrata. 
A cartografia artística é uma mapificação de um território a partir de uma experiencia física ou de um fato sensorial. Os mapas dos sons, odores, sentimentos, sensações, estados de ânimo, sonhos, etc. são tão necessários de serem realizados quanto os mapas topográficos, de estradas ou de redes de comunicação.

Há uma tipología de cartografías que são realizadas por artístas que são exploradores da realidade. Necessita-se de dotes de observação para captar uma geografía que não é estática, mas flutuante e difusa. O que define as cartografias artísticas é que o ponto de observação não está fixo, e o observador toma uma posição relativa e móvel para captar os matizes sutis e as diferentes ordens que aparentalmente estão ocultas no entorno daquilo que nos rodeia. Elie During, em Faux Raccords, estabelece uma espécie de cosmogoni na cidade em que o artista está especialmente dotado para captar esta realidade.

A cidade não é um exemplo trivial: ela constitui a atmosfera natural do artista [...] ela constitui uma fonte privilegiada de identificação da atividade artística. Além disso, ela reflete, em seu processo mesmo, uma questão de natureza cosmológica, que é justamente aquela da coexistência em uma mesma totalidade a priori aberta de uma pluralidade heterogênea de objetos, processos, pontos de vista, de espaços e durações próprias, que podem ser levadas a interagir, e então a se conectar. (During, 2010, p. 195) ${ }^{9}$

De fato, muitas das criações artísticas contemporâneas compõem um mapa conceitual, todavia para definir com mais rigor o que diferencia um desenho ou uma composição contemporânea de uma cartografia é o que definiremos como mapa: um suporte legível com um código de leitura. Uma cartografia transmite algum tipo de informção, e como em todo mapa, os signos que estão às margens da legenda do mapa nos informam o que queremos transmitir das normas e regras do jogo.

A Teoria do Caos nos adverte da impossibilidade de medir um território e realizar qualquer tentativa razoável e científica de establecer um mapa exato da realidade. Portanto, só é possível fazer uma aproximação e uma interpretação desta realidade complexa.

Benoit Mandelbrot sugere uma pregunta extremamente simples, mas sem resolução. Que medida exata tem a costa da Grã Bretanha? A resposta parece óbvia, mas se queremos

\footnotetext{
${ }^{9}$ Tradução do francês M.Gally.
} 
estabelecer uma magnitude numérica de uma costa, veremos impossibilidade desta ação. Nossa primeira aproximação seria medir a linha a partir de um mapa cartográfico ou uma imagem realizada por um satélite, mas em seguida veríamos que podemos conseguir uma maior precisão medindo a linha sinuosa da costa mediante cartas marinhas, muito mais exatas.

O seguinte passo, para alcançar essa extidão, consistiria em medir diretamente a costa in situ. Será neste momento de medição da realidade, que nos renderemos à evidência da complexidade: se medimos com a maré alta nos dará uma medição, com a maré baixa, outra, as ondas em fluxo ou refluxo nos alterarão os dados finais constantemente. Aparecerão pedras, rochas e elevações antes ou depois da passagem da água. Em qualquer circunsância nos dará medidas diferentes, a maioria das vezes extremamente diferentes, o que implica a inexatidão de um sistema pretendidamente científico. K. C. Cole, na sua obra "O Universo e a Xícara de Chá" nos demonstra a impossibilidade de medir elementos complexos.

Não é possível dissecar as matemáticas que subjazem na música de Mozart e experimentar, ao mesmo tempo, seu impacto emocional. Um Picasso contemplado sob a lente potente de um microscópio dissolve-se em uma pauta granular de pontos. Vista do espaço, a Terra revela-se como uma esfera, contudo, essa informaçãoo não oferece nenhum dado sobre o que está acontecendo no pátio do observador. Algo se perde em cada medição.

Um dos elementos intrínsecos da formulação de uma cartografia é a ideia de limite. $\mathrm{Na}$ cartografia tradicional, a noção de fronteira está estabelecida e é reconhecível simplesmente pela visão. Por outro lado, em uma experiência corporal no espaço, ou na cartografia de um sonho, de uma experiência, ou sensação, os limites são difusos.

Onde começa a paisagem? Nas árvores que constituem o fundo visual? Ou se nos estiramos nos chão, nas pequenas folhas que vemos diante de nossos olhos? Existem infinidades de limites e fronteiras em nossa construção da cidade. Existem limites entre as pessoas, fronteiras estabelecidas com os cheiros e os sons, entre os apartamentos de um edificio. São por estes limites difusos que nos interroga Joan Nogué na sua obra "Entre Paisajes".

Uma das entradas do vocábulo paisagem (paisaje) no Dicionário do Uso do Espanhol de Maria Moliner reza assim: extensão de campo visível a partir de um ponto específico [...]. Entende-se habitualmente por paisagem a panorânica que os nossos olhos percebem a partir de uma distância média [...]. O outro extremo da balança é a escala da imediatez, a mais próxima dos nossos olhos que aparece no primeiro plano ao andar pela cidade ou pelo campo. (Nogué, 2009, p. 197). 
A ideia de limite perdeu precisão.

A instalação L'Improbable Horizontal (2003-2009) do artista Eric La Casa é um dos exemplos de cartografia sonora de um lugar que conseguiu estabelecer esta rede entrecruzada. A referida instalação realizada no Castelo de Annecy é um observatório sonoro da paisagem centrado no tema dos diversos matizes do som da água ao redor do lago Annecy. O artista traça uma rede de pontos sonoros com a ajuda de um mapa topográfico mediante procedimentos geométricos, que fazem a relação entre a macrogeografia representada no mapa e os registros sonoros de microacontecimentos sonoros ou microsons das diferentes manifestações da água. O projeto implica na desmaterialização pontualista de sons que traçam uma cartografia do lugar. A instalação realizada nas janelas da torre do castelo e um corredor com alternância de luz e penumbra distribuem 60 registros sonoros mediante uma relação matemática segundo os pontos cardeais, cada número, 34 no total, está disposto em um eixo vertical subdividido em 13 níveis, que correspondem aos 13 lugares da escuta ao redor do lago. Vinte e seis composições de um minuto de duração se escutam de um modo aleatório durante o período da instalação sonora.

\section{REDES}

A cartografia artística é uma representação gráfica de um proceso dinâmico. É um sistema baseado na interação mediante a representação diagramática de trajetórias de uma ação expressadas em pontos, linhas, superficies. Estes diagramas são uma simulação de elementos dinâmicos capazes de adaptar-se, modificar-se, transformar-se e alterar-se dependendo dos fatores temporais.

Uma cartografia sonora é um registro de fluxos e trajetórias que tem a ver com o movimiento. Tanto o mapa gráfico, como o sonoro, tem implícita a ideia da trajetória, e, como movimento dinâmico que é, se combina com outro conceito: o de cruzamento; cruzamento de forças ou interseção de elementos móveis como nos indica Luis Martinez na sua obra Intersecciones:

Além de ser um conceito geométrico ou matemático, uma interseção é um encontro, um ajuste, o aviso de uma ligação que, dentre uma miríade de possibilidades, fez-se única e irrepetível. (Martínez, 2004, p. 7). 
A cartografia artística representa fluxos visíveis e invisíveis, é uma experiencia que une a experimentação e a interpretação da realidade cotidiana que opera simultaneamente numa esfera global e local ao mesmo tempo. $\mathrm{O}$ estudo se centra nos lugares marginais, quer dizer, nas zonas de tensão e conflito, onde se pruduzem mudanças bruscas de transformação urbana, movimentos migratórios, zonas de fricção ou articulação entre o urbano e a natureza. Nosso trabalho se situa nas confluências ou cruzamentos onde se produzem rompimentos e intercâmbios. Antonio Mengs nos detalha uma estratégia branda:

Quando falamos em estrutura, o conceito torna-se sinuoso, maleável, entreláça-se com o branco e flui como a água. (Mengs, 2004, p. 83)

O observatório de trasnformação urbana do som estabelece a gravação de sons dos espaços urbanos e zonas sensíveis de trasnformação urbanística, espaços residuais e lugares de fronteria entre realidades distintas para identificar seus componentes, configurar um material artístico que seja possível estudá-lo e difundi-lo. O trabalho de campo e a coleta de dados pretendem refletir a identidade sonora de cada espaço e establecer um registro que seja uma descrição sonora de um ambiente. O som é um documento que se pode analizar e preserva os aspectos diferenciados de cada lugar e permite comparações no tempo e em lugares diferentes. É importante definir as marcas sonoras que estruturam a geometria de uma cidade.

Poderíamos definir o espaço ao desviar nossa atenção do visual pela conformação dos sons ressoantes, das vibrações dos materiais e textura. De igual modo, o soar dos sinos de um monastério, em determinadas horas em Kioto, produz um mapa espacial da geometria de uma cidade em relação com os lugares. (Holl, 2011, p.30)

A mestiçagem cultural encobre fenômenos e situações extremamamente complexas. O mundo pós-moderno das cidades europeias está formado por uma cultura de montagem, mestiça e mesclada. Os sons mostram esta realidade emaranhada, uma mescla que se situa invarialvelmente entre a ambiguidade e a ambivalência.

A criação artística concebida como um pensamento poético tem ferramentas para mostrar e oferecer um novo olhar às mesclas e às mestiçagens, que são uma realidade em nossas cidades. O híbrido e o mestiço, não é só um indício passageiro de nossa sociedade, se não, um reflexo de um idioma planetário. Os marcos conceituais híbridos produzem novos modos de conhecimento que se manifestam mediante formas e expressões artísticas. O estudo 
desta realidade multiforme é um modo de conhecimento e, ao mesmo tempo, uma válvula de descompressão da tensão social.

O mundo moderno, homogêneo, coerente, deu um passo a um universo pós-moderno, fragmentado, heterogêneo e imprevisível. Espaços de mediação são necessários para dar uma resposta a um mundo complexo onde existem temporalidades distintas e formadas por um território composto por múltiplas dimensões. Os principais problemas de nosso tempo não podem ser entendidos separadamente, a sociedade não é um fenômeno linear, ou seja, tudo está interconectado e interdependente. Roger Lewin na sua obra "Complejidad, el Caos como generador de orden", nos expõe a ideia de não linearidade dos sistemas.

Completamente ordenado aqui, completamente aleatorio aqui [...] a complexidade se produz em algum lugar intermadiário [...] é uma questão de estrutura, de organização [...] estamos buscando as regras fundamentais que dão base a todos os sistemas, não apenas detalhes de qualquer um deles. (Lewin, 1995, p. 23)

Os estudos da complexidade dos fenômenos sociais não se resolvem mediante catalogação, mas mediante a organização do pensamento como uma dinâmica mestiça: juntar, mesclar, tramar, cruzar, sobrepor, transladar, fundir são movimentos que estão na base dos trabalhos criativos dos artistas sonoros que desenham um território urbano mediante um sistema de relações que nos ajudam a compreender as interferências. Os estudos dos lugares onde existe uma complexidade, produto da globalização, desvelam um conjunto de relações e de interconexões onde o conjunto é muito mais que a soma das partes isoladas. Nossa compreensão da complexidade da globalização colide com nossos hábitos mentais que conduzem a preferir conjuntos monolíticos aos espaços intermediários, já que é fácil identificar blocos sólidos (culturalmente) do que interstícios sem nome.

A Teoria da Complexidade, na essência, trata-se de uma teoría da impossibilidade de predizer [...]. Cada elemento, por si só, pode ser perfeitamente previsível. Mas ao reunir vários deles num grupo conseguirá nuvens, galáxias, uma mente, fenômenos, todos eles impredizíveis [...]. A razão é que nos sistemas complexos, cada parte influencia na atuação das demais, criando uma espessa trama de causas e efeitos tão entretecidos que não há modo de desenmaranhá-la. (Cole, 199, p.98)

Os lugares intersticiais e de confluência estão onde se situam a maioria dos trabalhos sonoros no entorno urbano, estes lugares intermediários cruzados entre os meios, são um encontro de estados diferentes e funções. Estas zonas de encontro são lugares muito dinâmicos onde a única condição permanente é a falta de estabilidade. Serge Gruzinski nos responde a pergunta que geralmente nos fazemos ao abordarmos estes mundos mesclados: 
temos que aceitá-los tal como se mostram, em vez de submetê-los a catalogações inúteis, aceita-los na sua multidimensionalidade, já que são produto de uma cultura híbrida resultado da montagem? Essa dissecação, que chamamos análises, projeta na maioria das vezes, nossas obsessões, nossos filtros em que vemos a realidade, nossos critérios fragmentados, e, sobretudo, nossa visão ocidental. Aceitar em sua realidade a realidade emaranhada, que se tem ante os olhos, é um primeiro passo positivo.

Estudar sonoramente as fronteiras é uma finalidade em nosso trabalho, o som, junto com os cheiros é a primeira manifestação da mudança. As fronteiras atuais são porosas, permeáveis, flexíveis e se locomovem. Num edificio de apartamentos, em qualquer de uma das cidades europeias, o primeiro sinal de mudança é o som, as novas palavras, músicas, outros ambientes sonoros que configuram as novas fronteiras entre um apartamento e outro, entre um edificio e o visinho. Alguns limites começam a se converter numa série de espirais, em uma frontera fractal que tem de ser estudada mediante outros mecanismos. O estudo sonoro destes lugares nos faz perceber da nossa incapacidade de conceber espaços entre dois mundos, é nessa realidade intermediária onde o som oferece graduações de uma complexidade indescritível.

Schopenhauer, no "Mundo como Vontade e Representação", nos faz uma descrição da ação penetrante e imediata que exerce o som em nossa percepção.

\begin{abstract}
A vista é o sentido do entendimento, que intui; o ouvido é o sentido da razão, que pensa e escuta [...]. Por isso os sons têm efeito sobre nosso espírito de forma pertubadora e hostil, ainda mais quando este for mais ativo e desenvolvido: eles rasgam todo o pensamento, transtor nam momentaneamente a força do pensar [...]. Esta oposição entre ambos os sentidos mostram-se também no fato de que os surdos, quando se curam por galvanismo, empalidecem mortalmente de horror ao ouvir o primeiro som. [...] Tudo isso é explicável em virtude de a faculdade da audição funcionar desde um abalo mecânico do nervo auditivo, que se propaga em seguida até o cérebro. (Schopenhauer, 1913, p.37)
\end{abstract}

O mapa sonoro nunca pode ser uma versão fidedigna da realidade, é uma aproximação e uma interpretação de um lugar num tempo definido. Um mapa sonoro, entendido como a cartografia aural de uma situação, é uma operação que reúne informações em vários níveis. Um esquema acústico elástico destinado a reconhecer o entramado de multiplas relações ocultas. Deveria ser um sistema gerado pela interação que se produz entre

\footnotetext{
${ }^{10}$ Tradução direta do alemão, M.Gally.
} 
camadas, que como todo mapa artístico é uma simulação de experimentação com a realidade, que não tem a finalidade de reproduzí-la, mas sim de conectar dimensões.

Para refletir os fluxos visíveis e invisíveis dos lugares onde operam simultaneamente espaços globais e espaços locais, necessita-se de outro tipo de ferramenta. A cartografia pode ser desmontável, reversível ou por dobras, com a finalidade de criar uma interconexão de camadas, de informação diversa. A cartografia social quer refletir acontecimentos e dinâmicas complexas como são os movimentos migratórios. O som nas zonas de tensão, reflete diferentes fluxos, redes e camadas, o mapa sonoro tem necesariamente que refletir esta construção dinâmica que se produz a cada instante em lugares de confluência.

Neste sentido, cabe destacar o excelente trabalho feito por José Manuel Berenguer em seu projeto "Sons em Causa" (Sonidos en Causa), cujos objetivos enumerados em sua página na internet expressam claramente essa finalidade de estudo dos lugares, onde é previsível uma mudança substancial no som:

\footnotetext{
"Sons em causa" é um projeto de registro do patrimônio sonoro próprio de uma série de contextos culturais latino-americanos, em cujo meio ambiente são previstas mudanças irreversíveis a curto e médio prazo por causa do crescimento econômico. A diversidade cultural e biológica latino-americanas é enorme. Merece ser levada em conta e ter divulgada sua grande importancia. O patrimônio intangível e, com ele, o sonoro, está seriamente ameaçado em muitos lugares do mundo. Uma vez operadas as mudanças inevitáveis, os sons, e com eles suas causas, desaparecerão para sempre. O trabalho conjunto de grupos artísticos e de pesquisa já existentes e com grande trajetória nos lugares escolhidos para se fazer os registros sonoros de "Sons em causa" é a ferramenta fundamental com a qual se pretende levar a cabo o objetivo principal do projeto, a saber, apoiar trabalhos de registro, preservação e difusão do patrimônio sonoro desses lugares escolhidos. (Orquestra do caos, n.d)
}

Quando falamos de camadas é algo que tem relação com o tempo ou, melhor dizendo, é uma relação fractal de tempo. Ensinaram-nos que o tempo é uma medida numérica, mas, o que a certa distância podemos considerar como uma linha, olhando detalhadamente, revela-se-nos com giros, curvas, arabescos de infinitos detalhes. De fato, em momentos especiais, de perigo ou acidente, temos o costume de desconectar do tempo mecânico do relógio para entrar em um tempo fractal, experimentando suas matises temporais e os microacontecimentos. Isto é o que ocorre diariamente quando sonhamos: uns poucos segundos podem conter uma ampla e complexa estória, que se manifesta mediante camadas sobrepostas, que em vigília não temos consciência, mas que nesta outra dimensão do sonho nos parece absolutamente lógica, mesmo que não resista a uma análise coerente. Esse estado temporal, relacionado à aleatoriedade, à casualidade e à coincidência, relaciona-se, como nos sugere Carl Gustav Jung, com o termo sincronicidade. A sincronicidade será a conexão de 
várias camadas da realidade. Esta concepção de interrelação do que aparentemente não está conectado, ou melhor, que não deveria estar objetivamente conectado, dá-nos uma nova dimensão no registro da complexidade social. A simultaneidade nos introduz em conceitos importantes enumerados por Elie During em "Faux Raccords: La coexistence des images".

Parece-nos que é a ideia de simultaneidade e a que vem junto com ela, aquela de
espaço, que talvez fosse necessário começar a complicar. É a face espacial do
problema da ubiquidade, cuja instantaneidade constitui a face temporal. A síntese
imediata dos acontecimentos ou fluxo distante é o principio que governa toda
totalização espacial quando esta procede de maneira global. (During, 2010, p.192)

A sincronicidade segundo Carl Gustav Jung é uma coincidencia significativa de padrões que se relacionam. As sucessões fortuitas também se agrupam e produzem padrões; estes padrões são uma ponte estendida entre o objetivo e o subjetivo, e tem significado ou valor para a pessoa que o experimenta. Esta coincidencia no tempo de duas ou mais sucessões relacionadas casualmente são um padrão de sucessões que têm um mesmo significado, cada nível implica sua própria descrição e está relacionado com os diferentes níveis que o rodeiam, mesmo que não tenham um fator de correlatividade.

A sincronicidade não se produz em apenas um nível, mas em vários níveis: é uma interconexão. É um bom exemplo de não linearidade, e tem a imagem de um quebra-cabeças; cada peça parte de um desenho originário da totalidade, mas somente por casualidade se juntam por um instante em que o todo concorda, mas que da mesma maneira se decompõe. Estas simetrias são dinâmicas e põem em jogo camadas da mente ocultas ou dobradas. Estas camadas da mente não podem ser retiradas diretamente da superfície a não ser que sejam deduzidas por impressões ou sombras. Os arquétipos deixam impressões na mente e projetam sombras por meio do pensamento. A obra de Michel Bitbol, De l'interieur du monde : pour une philosophie et une science des relations, desmembra este problema da relação entre níveis.

Nos procesos não lineares, acrescentar causas não leva à adição de dois efeitos correspondentes, o que frequentemente conduz a uma extrema ampliação dos efeitos (Bitbol, 2010, p.635) ${ }^{12}$.

\footnotetext{
${ }^{11}$ Tradução direta do francês, Miguel Gally.

12 Tradução direta do francês, Miguel Gally
} 
Michel Foucault é certamente o filósofo pós-moderno que melhor estudou as relações suscitadas pela cidade contemporânea. Em 1967 cunhou o termo "heterotopia", o qual define a nova visão do espaço urbano, que havia transformado o paradigma vigente até meados do século XX - que foi básicamente temporal - em uma relação espacial: o espaço do mundo contemporâneo é um espaço heterogêneo de lugares e relações, em contraposição ao espaço ordenado hierarquicamente da época moderna. Segundo o pensamento de Foucault vivemos dentro de uma rede de relações; o conceito de heterotopia faz referência a um espaço heterogêneo de lugares e relações que define com perfeição, não apenas a cidade contemporânea pós-moderna, mas também preconiza a rede global. Refletir este amálgama é uma exigência de interpretação; podemos construir esquemas bi ou tridimensionais que nos ajudem a orientarmo-nos nesta rede, como faz Santiago Ortiz, um dos artistas mais centrados na criação de mapas de relação dentro da internet; sua plataforma "Bestiário" é um compêndio de mapificação e cartografia: a plataforma MobilityLab da Universidade de Vic é outro grupo que desenvolve esta abordagem de cartografia interrelacionando redes digitais, mapas mentais e traçados urbanos, com os quais o Laboratório de Arte Sonora da Universidade de Barcelona tem colaborado em vários projetos. MobilityLab é formado por Efrain Foglia e Jordi Sala e foca a interrelação digital, e a criação de redes livres. Modo Mobil é o projeto mais conhecido do grupo; consiste em uma estação de transmissão livre que funciona como uma estrutura de telecomunicação sem fio. Este dispositivo permite a comunicação das redes da cidade no entorno urbano.

Air City é uma instalação tridimensional que se realiza no espaço real, e implica na confluência de dispositivos móveis (android ou iphone), que constrõem redes sem fio e se distribuem como mapas de pontos no espaço tridimensional e de som por meio de um dispositivo PureData. O projeto explora as possibilidades de ativar o espaço de um lugar físico. A instalação é um sistema por meio do qual o público pode ativar diferentes áreas de som mediante a exploração do espaço com um telefone celular. Em Air City São Paulo, no qual o autor deste artigo colaborou com Efrain Foglia e Jordi Sala, foi desenvolvido um mapa tridimensional que marcava os pontos invisíveis no espaço. Os participantes da instalação navegavam com o telefone celular dentro do espaço físico localizando e ativando localidades do som, estabelecendo assim uma composição sonora que narrava a paisagem sonora do bairro Bom Retiro em São Paulo.

Outro projeto com o qual colaboramos, Mobility Lab e Laboratori d'Art Sonor, foi o apresentado no festival de arte sonora Eufonic. A ação sonora do Laboratório de Arte Sonoro 
Eufonic consistiu na gravação de sons das diferentes manifestações da água por meio de hidrofones; o Mobility Lab também processou em tempo real os sons com uma ferramente especialmente desenhada para esta ação artística: eufonica-TwuitSynth, para conectar o entorno natural do delta com a rede global [internet] por meio do Twitter. O sistema está desenhado para interagir com os sons utilizando a rede Twitter para estabelecer uma comunicação entre uma ação desenvolvida no tempo real e no território, e a difusão e interação com as pessoas conectadas ao Twitter em tempo real.

O esquema de ação consiste em capturar o entorno do Delta de Ebro com registros de micropaisagens sonoras da água, processar os bits e convertê-los em palavras que se possam tuitar. As palavras são palavras autóctones do Delta, e se distribuem em três blocos temáticos: palavras do entorno natural, palavras que têm a ver com a interação da ação humana com o entorno natural e palavras específicas de elementos ou ações culturais. A cada palavra se atribuiu uma longitude de frequência dos sons gravados. As palavras em forma de hashtags de Twitter podem ser processadas como sons que correspondem às longitudes da onda: as pessoas que interagem com a ação, geralmente online, compõem frases a partir das palavras selecionadas, que gera uma composição aleatória de sons gravados.

Projeto de cartografia sonora da praça Salvador Segí do bairro Raval de Barcelona.

\begin{abstract}
O toponomista ia com as orelhas tapadas, nenhum som poderia distrai-lo, era ele mesmo que estava se ouvindo. O lugar ressoava dentro dele. O som era sempre produzido depois de um tempo de estar num lugar quieto e silencioso. Era um som seco que não se repetia, cada lugar fazia somente o primeiro golpe de anarhi e o som de cada lugar era diferente e genuíno como se fosse o ruído do lugar que estava imerso. (Perejaume , 1998 , p . 47)
\end{abstract}

Desde o curso 2010-2011 e com a previsão de que a construção da nova Filmoteca da Catalunha na Praça Salvador Seguí de Raval foi um motivo de transformação do bairro, propusemos a um grupo de artistas vinculados ao Laboratori del Caos da Licenciatura de Belas Artes, ao Mestrado de Criação Artística e ao Mestrado de Arte Sonora da Universidade de Barcelona fazer um acompanhamento das mudanças que se produziriam em um perímetro bem delimitado, a saber, a confluência das ruas Espalter, St. Pau e En Robador, tradicionalmente o centro nevralgico da prostituição de Barcelona, e desde os últimos anos lugar de acolhida das novas migrações. Estabelecemos pautas para unificar o trabalho quanto ao formato e referencial teórico da experiência. Em primeiro lugar, pedimos que cada colaborador selecionasse apenas um aspecto da complexidade desse lugar; um único e pontual 
centro de atenção para as múltiplas camadas que podemos relacionar com a praça no intuito de que posteriormente haja o acréscimo de todas as propostas e que elas sejam capazes de uma aproximação da realidade.

Pedimos que cada colaborador apresentasse o registro dos sons de uma camada sonora e, pelo menos, um diagrama gráfico ou da experiência, com apenas a exigência de anexar uma legenda de leitura do mapa. Quanto ao formato, estabelecemos uma forma única para a apresentação a partir de um A3 com um dobra na altura de $29,5 \mathrm{~cm}$, que configura um quadrado; na parte dobrada encontra-se a explicação gráfica ou legenda da cartografia, que se mostra visível ao desdobrar. Este design foi desenvolvido pela professora da ETS de Arquitetura de Barcelona, Dra. Andrea Ortega, para facilitar a sobreposição dos planos e a exposição das obras. Estas cartografias gráficas partem de algumas perguntas planejadas por John Berger em sua obra "Sobre el dibujo": "A criação de uma imagem começa ao se interrogar as aparências e ao se fazer certas marcas". (Berger, 2011, p.61)

\section{REFERÊNCIAS BIBLIOGRÁFICAS}

Alexander, Ch. (1971). Tres aspectos de matemática y diseño: La estructura del Medio Ambiente. Barcelona: Tusquets Ed.

Augé, M. (1992). Los no lugares. Espacios del anonimato .Una antropología de la sobremodernidad. Barcelona: Gedisa Editorial.

Berger, J.(2011). Sobre el dibujo. Barcelona: Gustavo Gili.

Boulez, P.(2003). Pli selon pli. Genéve: Contrechamp.

Bourgin, V.(2004). Ensayos. Barcelona: Gustavo Gili.

Breton, A.(1993). Lire le regard. Lovaine: Lachenal \& Ritter.

Briggs, J. \& Peat, D.(1999). Las siete leyes del caos. Barcelona: Grijalbo.

Bitbol, M.(2010). De l'interieur du monde. Pour une philosophie des relations. Paris: Flammarion.

Careri, F.(2002). Walkscapes. El andar como práctica estética. Barcelona: Gustavo Gili.

Certeau, M. de(1984). The Practice of Everyday Life. Berkeley: University of California Press. 
Chatwin, B.(1987). The Songlines. New York: Penguin Books.

Cole, K.C. (1999). El universo y la taza de té. Barcelona: Ediciones B.

Debord, G.(1999). Internacional situacionista, vol. I: La realización del arte. Madrid: Literatura Gris.

Deleuze, G. (1988). Diferencia y repetición. Gijón: Júcar Universidad. Delgado, M.(2007). Sociedades movedizas,. Pasops hacia una antropologia de las calles. Barcelona: Anagrama.

Diccionario Metápolis de Arquitectura Avanzada. (2001). Barcelona: Actar.

During, E.(2010). Faux raccords. Villa Arson: Actes Sud.

Escohotado, A. (1999). Caos y orden. Madrid: Espasa Calpe.

Foucault, M.(1997). Las palabras y las cosas. Una arqueología de las ciencias humanas. Madrid: Siglo XXI.

(1986). La pensée du dehors. Paris: Fata Morgana.

Gardner, M.(1995). Complejidad, el caos como generador de orden. Barcelona: Tusquets editores.

Gros, F.(2009) Marcher, une philosophie. París: Carnets Nord.

Gruzinsky, S.(2000). El pensamiento mestizo. Barcelona: Paidós Holgar, V.B. y Romero, F.(1998). Arte Fractal, estética del localismo.Braunchweig/Barcelona: ADI Arbeisstelle für Designinformátic.

Henry, M.(2008). Ver lo invisible. Madrid: Siruela.

Holl, S.(2011). Cuestiones de percepción. Barcelona: Gustavo Gili.

Keats, J.(2010). Belleza y verdad. Valencia: Ed. Pre-Textos.

Lynch, K.(1960). The image of the city. Cambridge: The Technology press and Harvard University press.

Martinez, L.(2004). Intersecciones. Madrid: Editorial Rueda.

Merleau-Ponty, M.(2002). Phenomenology of Perception. London: Routledge.

Mengs, A.(2004). Stalker de Andrei Tarkovsky. Madrid: Rialp.

Molderings, H.(2007). L'art comme expérience, les 3 stoppages étalon de Marcel Duchamp. París: Maison des Sciences de l'Homme. 
Morin, E.(2000). La mente bien ordenada. Barcelona: Seix Barral.

Nogué, A. y Canadell, E.(2010). Art i Ciència. Converses. Barcelona: Edicions UB.

Nogué, J.(2009). Entre Paisajes. Barcelona: Àmbit.

Orquesta del Caos (n.d.) Sonidos en causa. Revisado el 20 de noviembre de 2012 de http://www.sonoscop.net/sonoscop/sonidosencausa/index.html

Perec, G.(1999). Especie de Espacios. Barcelona: Montesinos.

---------- (2001). Pensar, clasificar. Barcelona: Gedisa. (2008). Lo infraordinario. Madrid: Impedimenta.

Perejaume,(1998). Oïsme. Barcelona: Proa.

Queneau, R.(1947). Exercise de Style. Paris: Editions Gallimard.

Schopenhauer, A. (1913). Die Welt als Wille und Vorstellung (Hrsg.Ludwig Berndl). Muenchen: Georg Mueller, Bd.2, §3 (p.37) [Edição usada pelo autor: El mundo como voluntad y representación. Madrid: Trotta, 2009].

Seel, M.(2003). Aesthetik des Erscheinens. Frankfurt a. Main: Suhrkamp, [Edição usada pelo autor: Estética del aparecer. Madrid: Katz editores, 2011].

Wagensberg, J.(2004). La Rebelión de las formas o cómo preservar cuando la incertidumbre aprieta. Barcelona: Metatemas23, libros para pensar la ciencia. 